\title{
Improving Careers Science: Ten Recommendations to Enhance the Credibility of Vocational Behavior Research \\ Cort W. Rudolph ${ }^{1}$ \\ ${ }^{1}$ Department of Psychology, Saint Louis University
}

Invited Editorial Submission for the JVB 50 th Anniversary Issue (2021)

Word Count: 4,866

This is a pre-print version of an in-press, accepted manuscript. Please cite as:

Rudolph, C. W. (2021). Improving careers science: Ten recommendations to enhance the credibility of vocational behavior research. Journal of Vocational Behavior, 126, 103560. https://doi.org/10.1016/j.jvb.2021.103560

\section{Author Note}

Cort W. Rudolph iD https://orcid.org/0000-0002-0536-9638

Cort W. Rudolph, Department of Psychology, Saint Louis University, St. Louis, MO (USA).

Correspondence concerning this article may be addressed to Cort W. Rudolph, Department of Psychology, Saint Louis University, Saint Louis MO (USA), e-mail: cort.rudolph@health.slu.edu

I would like to thank Hannes Zacher for his very helpful suggestions on an earlier version of this work. 


\begin{abstract}
With the $50^{\text {th }}$ anniversary of the Journal of Vocational Behavior, careers science has "come of age." From time-to-time, as a science matures, it is important to take stock of its approach to answering empirical questions - to ask whether or not "how we know what we know" is well founded and would lead one to conclude a firm grounding in rigorous, robust, and reproducible science. Over the past ten years, the field of psychology as a whole has experienced what some have called a "credibility revolution." That is, there is an increased focus on the way in which psychological research is conceptualized, conducted, reported, and applied. In the present article, I lay the groundwork for extending this credibility revolution to careers science. To inspire such a revolution, I provide ten recommendations, which serve as a means toward increasing the credibility of careers science and vocational behavior research. These ten recommendations reflect features of the research process which, if adopted universally, would bolster the credibility of careers science. The aim of this work is to offer guidance for moving the next 50 years of vocational behavior research forward in a way that inspires greater confidence in what our science offers, both theoretically and practically, to careers researchers and practitioners, and to the impact that this field has on society as a whole.
\end{abstract}

Keywords. Careers; Vocational Behavior; Research Methods; Critical Perspectives; MetaScience; Open Science; Credibility 


\section{Improving Careers Science: Ten Recommendations to Enhance the Credibility of Vocational Behavior Research}

\section{Introduction}

The $50^{\text {th }}$ anniversary of the flagship journal of careers science - the Journal of Vocational Behavior - is a testament to the longstanding importance of research on careers and vocational behavior. From time-to-time, it benefits any science to take stock of how it approaches the challenges of the research process (e.g., the notion of "self-correction" is a hallmark of science; Kuhn, 1970). Critical perspectives on the research process are important for the continuous development of theory, methodology, and practice as they challenge status-quo assumptions about what is deemed theoretically, methodologically, and practically appropriate. Such perspectives help guide judgements about what constitutes "good" research in a given domain.

Here, I focus on actionable ways to improve the credibility of careers science. Similar meta-perspectives on the research process have been impactful in other related fields in the organizational sciences (e.g., leadership; Antonakis, 2017). I present ten recommendations to bolster the credibility of careers science (see Table 1). This work is not meant as a critique per se of the direction that careers science has taken thus far; the focal articles in this issue attest to the broad, established impact of careers science. Rather, I offer recommendations for a new way forward, with an eye towards the next 50 years of the Journal of Vocational Behavior and for careers science at large. These recommendations are presented in the spirit if Merton's (1942/1973) notion of organized skepticism as a scientific norm, which offers that science should be free to engage in critical evaluations of its claims, and that no aspect of the process should be considered sacred, or undeserving of scrutiny. These recommendations reflect the zeitgeist in careers science, which has increasingly focused on promoting methodological advancements 
(e.g., consider the recent special issue on methodology in the Journal of Vocational Behavior; Volumes 120-121).

Given the central role that work plays in our lives, studying processes associated with careers, career development, and vocational behavior have myriad implications for individuals, organizations, and for society. It therefore behooves career scientists to adopt rigorous, robust, and reproducible approaches to their work. Ensuring the credibility of careers science is an ethical imperative, especially to the extent that the results of our work have bearing on the direction of people's careers (e.g., through the translation of this work into career counseling or development interventions, or into organizational policy). Given these impacts, we are obligated to ensure that the results of our work are trustworthy, that is, that our science is credible.

[Insert Table 1 Approximately Here]

\subsection{The credibility revolution: from psychological science to careers science. The}

term "credibility revolution" has been used to describe a recent period of self-examination and self-improvement aimed at bolstering the confidence in the results of the research process (see Chambers, 2019; Vazire, 2018). Credibility in this sense refers to a holistic judgment of the trust that we put in our research, and the degree to which judgements of such trust would be agreed upon. There have been numerous calls to adopt practices that promote transparency and openness to ensure credibility across (sub)disciplines of psychology (e.g., Hales et al., 2019) and allied fields in the organizational sciences (e.g., Banks et al., 2019). Careers science has been slower to adopt such practices, perhaps owing to its inherently multidisciplinary nature (e.g., diffusing responsibility across multiple fields obfuscates "what" constitutes credible research for careers science as a whole).

According to Vazire (2018), the changes that must be brought about to bolster credibility 
include implementing higher standards for the quantity and quality of evidence required to make strong scientific claims, the encouragement of direct replication, the preregistration of methods, decisions, and hypotheses, and ensuring greater transparency and openness in the research process. Considering these proposals, I next outline ten recommendations for the conduct of research in careers science, which would bolster its credibility. Then, recognizing that calling for change can be challenging, I consider potential counterpoints that would seek to maintain the status quo, which has served as the backdrop for research in careers science thus far. I conclude with general thoughts about what the development of a more rigorous, robust, and reproducible careers science means for the future of vocational behavior research, and what increasing the credibility of careers science would afford (e.g., to individuals, organizations, and to society).

\section{Ten Recommendations to Bolster the Credibility of Vocational Behavior Research}

2.1. Recommendation \#1: Carefully attend to theory and theorizing. Careers science needs to more carefully consider the role of theory and the process of theorizing to ensure the credibility of our science. The organizational sciences have been criticized for an obsession with novel theoretical contributions (i.e., "theorrhea"; see Antonakis, 2017). This obsession may contribute to theoretical groundings that are thready, or that offer incomplete considerations of the core tenets of the theory being proposed (i.e., "hand waving theorizing" wherein service is given to a theory to justify hypothesizing, but its core tenets are neither operationalized nor tested). This is not necessarily the fault of the researcher, and arguably two forces are at play here. First, editors and reviewers have been conditioned to demand novel theoretical contributions, and absent other substantive critiques to levy, may default to criticizing some aspect of the theoretical grounding or may offer advice to integrate post hoc corollary theorizing. This process can result in "frankentheorizing," whereby aspects of well-founded theories are 
informally stitched together, without true integration. Second, more systemically, psychological science and related disciplines have long been criticized for an overreliance on verbal theories (e.g., Harris, 1976) and a lack of formalized theories, which often leads to tangential theory borrowing rather than "true" theory testing.

It is likewise important to differentiate constructs from theories. Whereas theories specify formal relations among constructs, constructs in isolation do not theories make. As with theorizing, the organizational sciences (including careers science) has an obsession with constructs, especially those that are new and novel (i.e., "constructivitis"). Often constructs are developed outside of formal theories, resulting in "orphan constructs" (i.e., constructs looking for a theoretical home). Then, one of two processes occur: either theories are "bent" around new constructs, or new constructs are "wedged" into existing theories. Such construct compulsion can perhaps be considered a symptom of the broader disease of "neophilia" and is comorbid with "theorrhea" (see Antonakis, 2017). It is important to recognize that the novelty of any research endeavor is not a theory to be tested, and that the argument that "this has never been done before" is a weak justification for advancing novel ideas. I discuss related concerns below when noting the pitfalls of bandwagon fallacies.

To advance a more credible careers science, we need to work towards (re)formalizing existing theories and encouraging closer tests of such theories rather than hodge-podge theorizing in service of novelty. Thus, we need to prioritize and promote clear tests of existing theories over the development of new theories. We also need research to "clean up" theorizing by offering critical perspectives and building formal integrations among existing theories.

Finally, we need to curtail "constructivitis" and be especially critical of new constructs, lest we fall into the trap of "jingle" and "jangle" fallacies (see Kelley, 1927). 
2.2. Recommendation \#2: Recognize the limitations of methodology. Although theory and theorizing is important, it is also important to recognize that methodology goes hand-in-hand with theory. The conclusions drawn from any empirical study are only as valid as the methods that give rise to them. Thus, it is important to recognize the boundaries that methodology imposes on the conclusions drawn from research. Careers science has a longstanding tradition of employing a diverse array of methodologies, spanning qualitative (e.g., interviews, case studies) to quantitative (e.g., experimental, observational) methods. This diversity has benefited our science, however, the predominant methodology employed in careers science is still (typically) cross-sectional (i.e., single timepoint) survey designs. Methodologists have long lamented the limitations of such designs (e.g., Rindfleisch et al., 2008; Schmitt, 1994), and there are numerous issues to note when considering such designs, especially those that rely exclusively on single sources (e.g., self-reports) of data (e.g., endogeneity, Antonakis et al., 2010; common method bias, Cooper et al., 2020; equivalent models, Lee \& Hershberger, 1990). A more credible careers science could be built by curtailing research based solely upon cross-sectional methodologies, favoring instead approaches where evidence is triangulated across multiple methodologies (e.g., cross-sectional + longitudinal; experimental + observational; between person + within-person; qualitative + quantitative, etc.; see Kuorikoski \& Marchionni, 2016). In motivating this suggestion, it is important to note that research based solely on cross-sectional designs is already a prima facie reason for desk rejection at many journals in the organizational sciences.

Arguably, noting the flaws of cross-sectional designs represents a "low hanging fruit" critique. Indeed, it is important to recognize that all research designs are uniquely imperfect. For example, longitudinal research designs are no better for determining causal effects than cross sectional research designs, however they do at least partially make up for various shortcomings 
thereof (e.g., ensuring temporal ordering; controlling for baseline levels). Importantly, longitudinal designs are those with $3+$ observations that adopt a complete panel design (i.e., where all variables are measured at all timepoints; see Wang et al., 2017). Because they cannot control for baseline levels, incomplete panel designs (i.e., where different variables are measured at different timepoints) without baseline controls are essentially cross sectional, and the same caveats apply to results derived therefrom.

Observational research cannot readily justify causal claims. Thus, if causal inferences are of interest, the "gold standard" should be a design that closely approximates a randomized control trial (RCT). To this end, intervention studies that adopt RCT design features-true random assignment, true control groups (i.e., participation in an equivalent task, rather than "do nothing" conditions), baseline measures (e.g., the "two group pretest-posttest design," Shadish et al., 2002) should be favored. In summary, to bolster credibility, careers science needs to pay closer attention to research designs and the limitations of inferences drawn therefrom. Stronger evidence can be obtained by triangulating the results of studies that adopt diverse methodologies (e.g., through "full cycle" research designs that integrate knowledge from both qualitative and quantitative perspectives; see Chatman \& Flynn, 2005). Moreover, as discussed further below, there is an imperative for careers science to emphasize integrative methodologies to support cumulative science.

2.3. Recommendation \#3: Theory first, but also methods first. It should be clear that theory and methodology are inherently intertwined. However, it is important to recognize that theory is not enough to buoy poor methodology (Aguinis \& Vandenberg, 2014). All of the theory in the world will not save a poorly designed study. If, like many "models," the theory proposes a complex, multilevel, non-recursive, conditional, phased process that implies causal linkages (i.e., 
a representation akin to a subway map), then a cross-sectional self-report study will not suffice to provide a comprehensive or even marginally appropriate test thereof.

2.4. Recommendation \#4: Recognize the limitations of statistical models. Although methodologies limit the conclusions we can draw from our data, it is also important to recognize how such limitations translate into statistical models and parameter estimates. To this end, I want to point out a particularly nefarious practice - the testing of causal models with cross sectional data. It is well understood that it is not possible to unambiguously identify causal models with cross-sectional data (e.g., Kline, 2015; Maxwell et al., 2011; Pek \& Hoyle, 2016). It is therefore important to pay attention to the causal implications of one's statistical model, and especially in the case of cross sectional/observational studies that purport to test causal mediation. Statistical models are agnostic to their data; it is both possible and common to specify causal models based upon data for which causal inferences are untenable, because the model does not care about the design that gave rise to the data in the first place. Thus, a cross-sectional test of mediation does not tell us anything about the process that it is assumed to test.

There is a practical element to note here as well — consider how much time, which could be invested toward more worthwhile endeavors, is wasted collecting data for models that simply do not make sense. For example, cross-sectional mediation is conceptually identical to a test of incremental validity, which arguably answers a more interesting and useful question in a wide variety of circumstances (e.g., when conceptualizing "new" constructs). Importantly too, favoring novel statistical models is not the answer to these issues (e.g., see critiques of "partial least squares” by McIntosh et al., 2014; Rönkkö \& Evermann, 2013).

2.5. Recommendation \#5: Adopt modern approaches to statistical analysis. Research in careers science can be critiqued for a number of legacy statistical practices that are long due to 
be retired. To some extent, these practices represent "myths" about data analysis that are propagated in the way that we train researchers to conduct research. Although not comprehensive by any means, the six examples of such myths reported in Table 2 bear particular attention in the conduct of research in careers science, especially considering the goal of bolstering the credibility of research in this domain. Above all, considering these six examples, it is important to be cognizant of, and avoid falling victim to, the bandwagon fallacy when choosing and justifying analytic decisions (i.e., argumentum ad populum; "everyone else is doing it"). Each of these myths have propagated largely unchecked, in part because of such effects. Overall, the advice that "someone else did this once in a published empirical study" is a weak justification for the adoption of any theory, methodology, analytic decision, or statistical model.

[Insert Table 2 Approximately Here]

2.6. Recommendation \#6: Attend closely to measurement. There are two damming aspects of the research process that are often overlooked: measurement error and sampling error. Ensuring "good" measurement is the foundation of our work, and a credible careers science must attend to issues of measurement, and especially to the psychometric qualities (e.g., reliability, validity) of our scales, and to features of their use that mitigate measurement error. Although easy to ignore, controlling measurement error is perhaps one of the most important tasks a researcher faces, especially considering that parameter estimates are biased in the presence of such errors. There are numerous resources available that outline modern best practices in psychological measurement (e.g., Clark \& Watson, 2019; Goretzko et al., 2019; Heggestad et al., 2019) and with an eye towards improving methodological practice (e.g., Flake \& Fried, 2020).

That said, there are some common themes across these resources that bear mentioning here, especially given the observation that primary research often relies on "phantom validation" 
to justify the use of measures (i.e., the practice of re-using unvalidated measures across multiple studies, and justifying this practice via citing research that has used such unvalidated measures in the past; Friedberg, 2019). In building a more credible careers science, we can overcome these issues. For example, evidence from modern maximum likelihood exploratory and/or confirmatory factor analyses (i.e., rather than principal components analysis, which is not an appropriate psychometric model, Leandre et al., 2012; Raykov \& Marcoulides, 2008) may be offered to support the development and use of measures. Moreover, providing appropriate evidence for convergent and divergent validity, and appropriate reliability estimates (e.g., internal consistency estimates; $\omega)$. Where relevant (e.g., for longitudinal research; for research comparing multiple defined or pre-existing groups), evidence for measurement invariance must be provided (e.g., Millsap, 2012). Finally, in focusing on measurement, careers science must ensure best practices for the representation of latent variables (i.e., modeling item-level indicators, rather than "item parceling"; see Little et al., 2002).

2.7. Recommendation \#7: Focus on samples and sampling. Along with measurement error, sampling error is one of the two often-ignored "Achilles' heels" of psychological research. To build a more credible careers science, we must move toward a more critical consideration of the nature of our samples. Poor sampling limits the generalizability of our findings for a number of reasons, not least of which is the generally overlooked assumption that statistical inference assumes random sampling from the population. Moreover, statistical artefacts associated with sampling (e.g., selection effects resulting from attrition or range restriction; see Dahlke \& Wiernik, 2020) compound sampling error. Thus, a close consideration of sampling in primary empirical research, especially moving beyond an exclusive reliance on crowd sourced (e.g., MTurk; Matsakis, 2016; Moss \& Litman, 2018) and narrowly recruited convenience (e.g., 
WEIRD; Henrich et al., 2010) samples is warranted. Relatedly, the issue of participant compensation, the ethics of participant payments, and the resulting motivations of paid participants must be acknowledged. As it is possible, panel respondents should be paid commensurate with the prevailing wage for their region, and researchers should consider the use of survey research platforms (e.g., Prolific) that require fair compensation.

The relative merits and deficiencies of any given sampling strategy can be debated (see Highhouse \& Gillespie, 2009; Landers \& Behrend, 2015), however the broader point here is to consider how careers science phenomena manifest across different samples. To enact this, we need to encourage and reward the production of well designed, "high- $n$ " studies based on purposefully broad and representative samples, and the production of studies that triangulate findings across multiple samples and methodologies. To this end, a focus on cumulation will also help to address concerns about sampling (e.g., as meta-analysis is well-geared for addressing questions about generalizability on the basis of sample characteristics; see Rudolph et al., 2020)

\subsection{Recommendation \#8: Replicate, integrate, and critically examine. Psychology} has been faced with a credibility crisis stemming in part from notable failures of replication (e.g., Klein et al., 2018). To enhance the credibility of careers science, a greater focus on replicability is necessary, as is an enhanced focus on cumulative- and meta-science. Although core to the scientific process, to date, replication efforts have been to some extent eschewed by various literatures, largely owing to their perceived lack of novelty (e.g., "neophilia"; Antonakis, 2017). To overcome this, researchers should be encouraged to conduct direct and constructive replication studies, and careers science should prioritize such efforts. In particular, constructive replication studies are those that are designed to reproduce and extend (i.e., theoretically and empirically) research findings (see Lykken, 1968). Such extension may come from the 
consideration of different samples, different measures of the same constructs, or through different methodologies.

There is a pressing need to integrate and critically examine existing literature. To this end, Chalmers (2006, p. 1) has referred to "the scandalous failure of scientists to cumulate scientifically," offering that new research must begin with a systematic assessment of what is already known from existing research to situate new knowledge within available evidence. To move careers science forward, we need to support a culture that moves the imperative of integration - both theoretical and conceptual - to the forefront. To date, careers science has generally encouraged the synthesis and cumulation of evidence through various means, as represented by the content published in the Journal of Vocational Behavior. Indeed, the integrative papers that are contained within this volume are a testament to this, as are the various “annual review" issues (e.g., Vol. 116) and the long-standing publication of meta-analytic reviews (Rudolph et al., 2020). However, broader efforts focused on summarizing evidencebased practice should be advanced, and have been fruitful in other domains (e.g., the U.S. Department of Education's "What Works" clearinghouse; the Center for Evidence Based Management). There is a need for integrative resources regarding evidence-based practice in careers science, especially among vocational behavior interventions. Moreover, it is important to adopt a critical perspective in synthesizing research, asking questions about "what works" and "what does not." This especially includes critically examining "new" and "novel" constructs.

\subsection{Recommendation \#9: Pre-register hypotheses, methodological choices, and}

analyses. The remaining two recommendations pertain to structural elements of the research process that can be generally couched as “open science practices." First, we need to normalize the expectation that researchers will pre-register study hypotheses, methodological choices, and 
analyses. The broader point of this recommendation is to ensure the separation of confirmatory from exploratory analyses. Indeed, we need both confirmatory and exploratory research, but exploratory research masquerading as confirmatory is a liability to the broader credibility of careers science. The practice of preregistration puts checks in place that curtail "researcher degrees of freedom" (e.g., " $p$-hacking") and issues associated with the "forking paths problem" (Gelman \& Loken, 2014).

The architecture for this suggestion is already in place and has been adopted in other fields with much success. There are numerous means of preregistration (e.g., the Open Science Framework; OSF). Researchers should also take advantage of alternative publication submission formats (e.g., results blind reviews; registered reports; see Nosek \& Lakens, 2014). Although the Journal of Vocational Behavior allows for results blind reviews, it does not allow for a registered reports format at this time. However, given the imperative of advancing a more credible careers science, it is perhaps time that we consider this submission option.

\subsection{Recommendation \#10: Make data, code, materials and all products of the}

research process open. The final recommendation here is to encourage a culture of open science practices in careers science, including especially pushing for open access. This recommendation can be summarized in a single phrase — make all products of the research process open. This includes making manuscripts, but also data, code, and materials, open and available to all, rather than being "stuck" behind journal paywalls or researchers' file drawers, which limit open access. My recommendation goes beyond the imperative of open access, and additionally encourages researchers to pay attention to the completeness and accuracy with which their results are presented (e.g., attending to appropriate reporting of statistics, standard errors, degrees of freedom, fit indices; see also Zhang \& Shaw, 2012). As with preregistration, there already exist a 
number of tools to facilitate the adoption of this suggestion. For example, OSF allows for the posting of research materials, including data and code. OSF repositories can also be linked to preprint servers (e.g., PsyArXiv) for the posting of pre-print versions of manuscripts. Thus, it is possible via OSF for (a) preregistration, (b) data, materials, and results, and (c) manuscripts to be linked together, and made openly available. Careers science should move toward a model of openness in the research process, which will enhance the transparency of our work thus bolstering credibility, but also democratize the availability of our evidence in service of a more impactful science.

\section{Anticipating Potential Critiques of These Suggestions.}

The preceding ten recommendations offer a glimpse at how careers science can increase its credibility by adopting practices that support more rigorous, robust, and reproducible research. Although there is great promise in the notion of enhanced credibility, some of these suggestions may frustrate researchers who are content with the status quo (e.g., Fiske, 2016). However, I also suspect that, for many readers, these suggestions will serve to validate and advance already robust programs of research. Either way, it is important to recognize that we are both the products and produces of our own status quo - the "way we do things" is a constructed phenomenon. Science is an agentic exercise; just as easily as we succumb to the way in which things have always been, so too can we change how things will be.

Importantly, these recommendations are not inherently controversial. The core ideas that underlie the credibility revolution reflect values that are inherent to what we already know about the way science "should" be conducted; adopting practices that bolster credibility better approximates the ideal form of the scientific process. That said, I recognize that these ideas will not be without detractors and anticipate a number of critiques of the ideas that I have presented. 
First, these suggestions preclude longstanding field-by-field differences in the traditions, norms, and approaches to studying career-related phenomena (e.g., in psychology, management, and organizational behavior). Although I would agree, I would also say that the suggestions offered here provide an opportunity to pave a single path forward, and to develop a common set of standards that career scientists_-regardless of field, discipline, theoretical tradition, et cetera - hold ourselves to. These standards should be those that maximize the credibility of our science; those that promote rigorous, robust, and reproducible research. In adopting such standards, we must reject the notion that different subfields of careers science are held to different standards of quality, and instead adopt the idea that careers science as a whole strives to uphold rigorous research practices.

Second, it could be argued that, owing to the difficulty associated with studying certain populations, that there should be affordances made for different levels of rigor on the basis of such challenges. For example, it could be argued that certain phenomena can only be studied via certain methodologies owing to sampling issues (i.e., access to a subpopulation). This point is often held up to justify conducting "low- $n$ " cross-sectional studies, often using narrative, qualitative, or case study methods. It is important to recognize that challenges accessing certain populations, and the sampling issues that result from this, do not relieve researchers of their duties as scientists. Moreover, it could be argued that studying small, convenient cross sections of already narrow corners of larger populations does little to advance the broader applicability of careers science.

Third, I have made the point, echoed by others, that novelty is overemphasized in research. Still, some have argued that theoretical and/or conceptual novelty precludes rigoressentially that "new" ideas can be studied with less rigor, because novelty is a contribution in- 
and-of itself and the challenges of managing novelty afford latitude to consider less-robust methodologies (e.g., Baumeister, 2016). This argument is often made to support the goal of discovery around emergent contemporaneous phenomena. However, this argument does not support the encouragement of credible science. Considering how evidence flows through the scientific process, new ideas need to be studied with even more rigor than old ideas (e.g., to situate new evidence within the broader "picture" of existing evidence), and old ideas should be subject to constant (re)assessment, replication, and critique.

Fourth, it could be argued that people will not participate in open science because it is overly draconian, bureaucratic, and requires additional effort for researchers, reviewers and editors, and journals. It might also be argued that these suggestions disadvantage early career researchers, or those who lack resources. These critiques are intertwined with the reward system that surrounds the publication process, and the value that publications have for academics. Arguably, academia "rewards A" (i.e., publishing volume) while "hoping for B" (i.e., publishing credible science) (Kerr, 1975). Incentivizing open science practices and prioritizing rigorous research over publication volume would help to address this, however I recognize that this is a norm that will be challenging to change. It is important to point out that the field of psychology as a whole has started to canonize the practices outlined here, for example, the American Psychological Association (APA) recently signed on to the Transparency and Openness Promotion (TOP) guidelines, all but requiring the advancement of more rigorous research practices as a precondition for submitting to APA journals (Center for Open Science, 2020).

Some may see these suggestions as proposing a need to "standardize" research, therefore inhibiting creativity (e.g., Baumeister, 2016). I would argue that the standardization of rigor in service of credibility is a benefit of this perspective, and that shifting the creative focus of the 
research process to a priori (i.e., study design, theory building) rather than post hoc (i.e., $p$ hacking) efforts is enormously beneficial. Finally, most of these suggestions could be critiqued by offering that the general move towards enhanced credibility assumes that all research adopts a positivist lens. However, these suggestions could apply broadly to other theories of knowledge (e.g., an approach to credible interpretivist or phenomenological perspectives could be proposed; see the APA JARS guidelines, Levitt et al., 2018). That said, I know of no means of generating knowledge that is as efficient as that promoted by positivism.

\section{Conclusions}

Fully recognizing that calling for a credibility revolution in careers science serves as a provocation, I also acknowledge that my suggestions themselves are not without limitations, and welcome criticism to this end. Still, I am optimistic that these suggestions will serve as a "roadmap" or "playbook" for research on careers and vocational behavior for the next 50 years. To paraphrase from Platt (1964), rigorous, robust, and reproducible research is the engine by which careers science will move forward. Hopefully, the next 50 years of the Journal of Vocational Behavior will be noted for an increased focus on the credibility of careers science.

In motivating this "revolution," the impacts of a more credible careers science on society as a whole should not be overlooked. With the increasingly dynamic nature of work, the imperatives of careers science should be even more apparent. Given the notable impacts that careers science has on individual level outcomes (e.g., health, wellbeing, career success) across the lifespan (see Zacher \& Froidevaux, 2021 in this issue) the development of a more rigorous, robust, and reproducible careers science has implications that extend beyond research in vocational behavior, with consequences for organizations, broader economies, and for the development of society as a whole. Thus, my hope in presenting these ideas is to inspire the next 
50 years of research in the Journal of Vocational Behavior to adopt practices that maximize the credibility of careers science. 


\section{References}

Aguinis, H., \& Vandenberg, R. J. (2014). An ounce of prevention is worth a pound of cure: Improving research quality before data collection. Annual. Review of Organizational Psychology and Organizational Behavior, 1(1), 569-595. http://dx.doi.org/10.1146/annurev-orgpsych-031413-091231

Antonakis, J. (2017). On doing better science: From thrill of discovery to policy implications. The Leadership Quarterly, 28(1), 5-21. http://dx.doi.org/10.1016/j.leaqua.2017.01 .006

Antonakis, J., Bendahan, S., Jacquart, P., \& Lalive, R. (2010). On making causal claims: A review and recommendations. The Leadership Quarterly, 21(6), 1086-1120. https://doi.org/10.1016/j.leaqua.2010.10.010

Banks, G. C., Field, J. G., Oswald, F. L., O’Boyle, E. H., Landis, R. S., Rupp, D. E., \& Rogelberg, S. G. (2019). Answers to 18 questions about open science practices. Journal of Business and Psychology, 34(3), 257-270. https://doi.org/10.1007/s10869-018-9547-8

Baumeister, R. F. (2016). Charting the future of social psychology on stormy seas: Winners, losers, and recommendations. Journal of Experimental Social Psychology, 66, 153-158. https://doi.org/10.1016/j.jesp.2016.02.003

Center for Evidence Based Management. (N.D.). https://cebma.org

Center for Open Science (2020). APA Joins as New Signatory to TOP Guidelines. https://www.cos.io/about/news/apa-joins-as-new-signatory-to-top-guidelines

Chalmers, I. (2006). The scandalous failure of scientists to cumulate scientifically. Abstract to 
paper presented at: Ninth World Congress on Health Information and Libraries; 2005 Sep 20-23; Salvador, Brazil. (Available online: http://www.icml9.org/program/activity. php?lang=en\&id=36)

Chambers, C. (2019). The seven deadly sins of psychology: A manifesto for reforming the culture of scientific practice. Princeton University Press.

Chatman, J. A., \& Flynn, F. J. (2005). Full-cycle micro-organizational behavior research. Organization Science, 16(4), 434-447. http://dx.doi.org/10.1287/orsc.1050.0136

Clark, L. A., \& Watson, D. (2019). Constructing validity: New developments in creating objective measuring instruments. Psychological Assessment, 31(12), 14121427. https://doi.org/10.1037/pas0000626

Cohen, J. (1990). Things I have learned (so far). American Psychologist, 45(12), 1304-1312. https://doi.org/10.1037/0003-066X.45.12.1304

Cooper, B., Eva, N., Fazlelahi, F. Z., Newman, A., Lee, A., \& Obschonka, M. (2020). Common method variance in vocational behavior research: Reviewing the state of the literature. Journal of Vocational Behavior. https://doi.org/10.1016/j.jvb.2020.103472

Dahlke, J. A., \& Wiernik, B. M. (2020). Not restricted to selection research: Accounting for indirect range restriction in organizational research. Organizational Research Methods, 23(4), 717-749. https://doi.org/10.1177/1094428119859398

Fiske, S. T. (2016). A call to change science's culture of shaming. APS Observer, 29(9). Retrieved from: https://www.psychologicalscience.org/observer/a-call-to-changesciences-culture-of-shaming

Flake, J. K., \& Fried, E. I. (2020). Measurement Schmeasurement: Questionable Measurement Practices and How to Avoid Them. Advances in Methods and Practices in 
Psychological Science. https://doi.org/10.31234/osf.io/hs7wm

Friedberg, M. (2019, July 15). Phantom validation: The practice of reusing the same unvalidated measure across multiple studies, citing the first study that used the (still unvalidated) measure as precedent for using it. [Twitter Post]. Retrieved from https://twitter.com/mwfriedberg/status/1150746932123451394.

Gelman, A. , \& Loken, E. (2014). The statistical crisis in science: data-dependent analysis-a “garden of forking paths"- explains why many statistically significant comparisons don't hold up. American Scientist, 102, 460. https://doi.org/10.1511/2014.111.460

Goretzko, D., Pham, T. T. H., \& Bühner, M. (2019). Exploratory factor analysis: Current use, methodological developments and recommendations for good practice. Current Psychology, 1-12. https://doi.org/10.1007/s12144-019-00300-2

Hales, A. H., Wesselmann, E. D., \& Hilgard, J. (2019). Improving psychological science through transparency and openness: An overview. Perspectives on Behavior Science, 42(1), 1331. https://doi.org/10.1007/s40614-018-00186-8

Harrell, F. (2020). Problems Caused by Categorizing Continuous Variables. Retrieved from: http://biostat.mc.vanderbilt.edu/wiki/Main/CatContinuous

Harris, R. J. (1976). The uncertain connection between verbal theories and research hypotheses in social psychology. Journal of Experimental Social Psychology, 12(2), 210-219. https://doi.org/10.1016/0022-1031(76)90071-8

Heggestad, E. D., Scheaf, D. J., Banks, G. C., Monroe Hausfeld, M., Tonidandel, S., \& Williams, E. B. (2019). Scale adaptation in organizational science research: A review and bestpractice recommendations. Journal of Management, 45(6), 2596-2627. https://doi.org/10.1177/0149206319850280 
Henrich, J., Heine, S. J., \& Norenzayan, A. (2010). Most people are not WEIRD. Nature, 466(7302), 29-29.

Highhouse, S., \& Gillespie, J. Z. (2009). Do samples really matter that much? In C. E. Lance \& R. J. Vandenberg (Eds.), Statistical and methodological myths and urban legends: Doctrine, verity and fable in the organizational and social sciences (pp. 247-265). New York: Routledge.

Hox, J. J., Moerbeek, M., \& Van de Schoot, R. (2017). Multilevel analysis: Techniques and applications. New York: Routledge.

Huang, F. L. (2020). MANOVA: A procedure whose time has passed?. Gifted Child Quarterly, 64(1), 56-60. https://doi.org/10.1177/0016986219887200

Kelley, T. L. (1927). Interpretation of educational measurements. Yonkers-on-Hudson, N.Y: World Book Company.

Kerr, S. (1975). On the folly of rewarding A, while hoping for B. Academy of Management Journal, 18(4), 769-783. http://dx.doi.org/10.5465/255378

Klein, R. A., Vianello, M., Hasselman, F., Adams, B. G., Adams Jr, R. B., Alper, S., ... \& Batra, R. (2018). Many Labs 2: Investigating variation in replicability across samples and settings. Advances in Methods and Practices in Psychological Science, 1(4), 443-490. https://doi.org/10.1177/2515245918810225

Kline, R. B. (2015). The mediation myth. Basic and Applied Social Psychology, 37(4), 202-213. https://doi.org/10.1080/01973533.2015.1049349

Kuorikoski, J., \& Marchionni, C. (2016). Evidential diversity and the triangulation of phenomena. Philosophy of Science, 83(2), 227-247. http://dx.doi.org/10.1086/684960 Kuhn, T. S. (1970). The structure of scientific revolutions. Chicago, IL: University of Chicago 
Press.

Landers, R. N., \& Behrend, T. S. (2015). An inconvenient truth: Arbitrary distinctions between organizational, Mechanical Turk, and other convenience samples. Industrial and Organizational Psychology, 8(2), 142-164. http://dx.doi.org/10.1017/iop.2015.13

Leandre, R., Fabrigar, L. R., \& Wegener, D. T. (2012). Exploratory factor analysis. Oxford, UK: Oxford University Press.

Lee, S., \& Hershberger, S. (1990). A simple rule for generating equivalent models in covariance structure modeling. Multivariate Behavioral Research, 25(3), 313-334. https://doi.org/10.1207/s15327906mbr2503_4

Levitt, H. M., Bamberg, M., Creswell, J. W., Frost, D. M., Josselson, R., \& Suárez-Orozco, C. (2018). Journal article reporting standards for qualitative primary, qualitative metaanalytic, and mixed methods research in psychology: The APA Publications and Communications Board task force report. American Psychologist, 73(1), 26-46. http://dx.doi.org/10.1037/amp000015

Little, T. D., Cunningham, W. A., Shahar, G., \& Widaman, K. F. (2002). To parcel or not to parcel: Exploring the question, weighing the merits. Structural equation modeling, 9(2), 151-173. doi: /10.1207/S15328007SEM0902_1

Lykken, D. T. (1968). Statistical significance in psychological research. Psychological Bulletin, 70(3), 151-159.

Matsakis, L. (2016). The unknown, poorly paid labor force powering academic research. Vice. Retrieved from: https://www.vice.com/en/article/8q8ggb/the-unknown-poorly-paid-laborforce-powering-academic-research

Maxwell, S. E., Cole, D. A., \& Mitchell, M. A. (2011). Bias in cross-sectional analyses of 
longitudinal mediation: Partial and complete mediation under an autoregressive model. Multivariate Behavioral Research, 46(5), 816-841.

https://doi.org/10.1080/00273171.2011.606716

McIntosh, C. N., Edwards, J. R., \& Antonakis, J. (2014). Reflections on partial least squares path modeling. Organizational Research Methods, 17(2), 210-251. https://doi.org/10.1177/1094428114529165

Merton, R. K. (1973). The sociology of science: Theoretical and empirical investigations. Chicago, IL: University of Chicago Press. (Original work published 1942)

Millsap, R. E. (2012). Statistical approaches to measurement invariance. New York: Routledge. Moss, A., \& Litman, L. (2018). After the bot scare: Understanding what's been happening with data collection on MTurk and how to stop it. CloudResearch Retrieved from: https://www.cloudresearch.com/resources/blog/after-the-bot-scare-understanding-whatsbeen-happening-with-data-collection-on-mturk-and-how-to-stop-it/

Nosek, B. A. , \& Lakens, D. (2014). Registered reports: A method to increase the credibility of published results. Social Psychology, 45, 137-141. https://doi.org/10.1027/18649335/a000192

Pek, J., \& Hoyle, R. H. (2016). On the (in) validity of tests of simple mediation: Threats and solutions. Social and Personality Psychology Compass, 10(3), 150-163. https://doi.org/10.1111/spc3.12237

Platt, J. R. (1964). Strong inference. Science, 146(3642), 347-353.

Pritschet, L., Powell, D., \& Horne, Z. (2016). Marginally significant effects as evidence for hypotheses: Changing attitudes over four decades. Psychological Science, 27(7), 10361042. 
Raykov, T., \& Marcoulides, G. A. (2008). An introduction to applied multivariate analysis. New York: Routledge.

Raudenbush, S. W., \& Bryk, A. S. (2002). Hierarchical linear models: Applications and data analysis methods. Thousand Oaks, CA: SAGE.

Rindfleisch, A., Malter, A. J., Ganesan, S., \& Moorman, C. (2008). Cross-sectional versus longitudinal survey research: Concepts, findings, and guidelines. Journal of Marketing Research, 45(3), 261-279. http://dx.doi.org/10.1509/jmkr.45.3.261

Robins, J. M., van der Vaart, A., \& Ventura, V. (2000). Asymptotic distribution of p values in composite null models. Journal of the American Statistical Association, 95(452), 1143 1156. https://doi.org/10.1080/01621459.2000.10474310

Rönkkö, M., \& Evermann, J. (2013). A critical examination of common beliefs about partial least squares path modeling. Organizational Research Methods, 16(3), 425-448. https://doi.org/10.1177/1094428112474693

Rubin, M. (2017). An evaluation of four solutions to the forking paths problem: Adjusted alpha, preregistration, sensitivity analyses, and abandoning the Neyman-Pearson approach. Review of General Psychology, 21(4), 321-329. https://doi.org/10.1037/gpr0000135

Rudolph, C. W., Chang, C. K., Rauvola, R. S., \& Zacher, H. (2020). Meta-analysis in vocational behavior: A systematic review and recommendations for best practices. Journal of Vocational Behavior, 118, 103397. https://doi.org/10.1016/j.jvb.2020.103397

Schmitt, N. (1994). Method bias: The importance of theory and measurement. Journal of Organizational Behavior, 393-398. http://dx.doi.org/10.1002/job.4030150504

Shadish, W. R., Cook, T. D., \& Campbell, D. T. (2002). Experimental and quasi-experimental designs for generalized causal inference. Boston: Houghton Mifflin,. 
Smith, K. N., Lamb, K. N., \& Henson, R. K. (2020). Making Meaning out of MANOVA: The Need for Multivariate Post Hoc Testing in Gifted Education Research. Gifted Child Quarterly, 64(1), 41-55. https://doi.org/10.1177/0016986219890352

Snijders, T. A., \& Bosker, R. J. (2011). Multilevel analysis: An introduction to basic and advanced multilevel modeling. Thousand Oaks, CA: SAGE.

U.S. Department of Education. (N.D.) Institute of Education Sciences, National Center for Education Evaluation and Regional Assistance, What Works Clearinghouse. https://ies.ed.gov/ncee/wwc/FWW

Vazire, S. (2018). Implications of the credibility revolution for productivity, creativity, and progress. Perspectives on Psychological Science, 13(4), 411-417. http://dx.doi.org/10.1177/1745691617751884

Wang, M., Beal, D. J., Chan, D., Newman, D. A., Vancouver, J. B., \& Vandenberg, R. J. (2017). Longitudinal research: A panel discussion on conceptual issues, research design, and statistical techniques. Work, Aging and Retirement, 3(1), 1-24. https://doi.org/10.1093/workar/waw033

Zacher, H. \& Froidevaux, A. (2021, In Press). Life stage, lifespan, and life course perspectives on vocational behavior and development: A theoretical framework, review, and research agenda. Journal of Vocational Behavior. https://doi.org/10.1016/j.jvb.2020.103476

Zhang, Y., \& Shaw, J. D. (2012). Publishing in AMJ-Part 5: Crafting the methods and results. Academy of Management Journal, 55(1), 8-12. https://doi.org/10.5465/amj.2012.4001 
Table 1. Overview of Recommendations for Enhancing the Credibility of Careers Science.

\begin{tabular}{|c|c|}
\hline $\begin{array}{l}\text { Recommendations to } \\
\text { Enhance Credibility }\end{array}$ & $\begin{array}{c}\text { Advice for } \\
\text { Enacting Recommendations }\end{array}$ \\
\hline \#1: Carefully attend to theory and theorizing. & $\begin{array}{l}\text { - Articulate linkages between theory and hypotheses. } \\
\text { - Encourage and reward (re)formalizing theory as a research goal. } \\
\text { - Avoid "hand waving theorizing" and "frankentheorizing." }\end{array}$ \\
\hline \#2: Recognize the limitations of methodology. & $\begin{array}{l}\text { - Align hypotheses with appropriate methodologies. } \\
\text { - Recognize the limits of causal inference via-à-vis study design. } \\
\text { - Curtail the use of cross-sectional research designs. }\end{array}$ \\
\hline \#3: Theory first, but also methods first. & $\begin{array}{l}\text { - Design studies to test theory. } \\
\text { - Recognize that theory and methodology are intertwined. } \\
\text { - Propose theories that are actually testable, not just heuristic models. }\end{array}$ \\
\hline \#4: Recognize the limitations of statistical models. & $\begin{array}{l}\text { - Acknowledge the causal implications of various statistical models. } \\
\text { - Understand that models are agnostic to data. } \\
\text { - Adopt a critical perspective on statistical modeling approaches. }\end{array}$ \\
\hline \#5: Adopt modern approaches to statistical analysis. & $\begin{array}{l}\text { - Integrate current thinking about statistical analysis into the research process. } \\
\text { - Avoid falling victim to common analysis "myths." } \\
\text { - Recognize that legacy practice is a weak justification for analytic choices. }\end{array}$ \\
\hline \#6: Attend closely to measurement. & $\begin{array}{l}\text { - Acknowledge and take steps to mitigate measurement error. } \\
\text { - Treat psychometrics with the same rigor as every component of the research process. } \\
\text { - Adopt modern approaches to psychometrics in scale development and use. }\end{array}$ \\
\hline \#7: Focus on samples and sampling. & $\begin{array}{l}\text { - Recognize and take steps to mitigate sampling error. } \\
\text { - Recruit large, representative samples. } \\
\text { - Discourage small, convenience samples. }\end{array}$ \\
\hline \#8: Replicate, integrate, and critically examine. & $\begin{array}{l}\text { - Encourage and reward the conduct of direct and conceptual replication studies. } \\
\text { - Synthesize existing evidence through systematic reviews and meta-analyses. } \\
\text { - Consider critical reviews of theories, methodologies, and practices. }\end{array}$ \\
\hline $\begin{array}{l}\text { \#9: Pre-register hypotheses, methodological choices, and } \\
\text { analyses. }\end{array}$ & $\begin{array}{l}\text { - Demand pre-registration of hypotheses, methods, and analyses. } \\
\text { - Demarcate "confirmatory" from "exploratory" research. } \\
\text { - Encourage exploratory research. }\end{array}$ \\
\hline $\begin{array}{l}\text { \#10: Make data, code, materials and all products of the research } \\
\text { process open. }\end{array}$ & $\begin{array}{l}\text { - Encourage open-science practices. } \\
\text { - Make data and code available to editors, reviewers, and the public. } \\
\text { - Post pre-prints of working manuscripts and pre-press work to encourage open access. }\end{array}$ \\
\hline
\end{tabular}


Table 2. Example Statistical Myths and Realities

\begin{tabular}{|c|c|c|}
\hline Myth & $\begin{array}{c}\text { Statistical } \\
\text { Issue }\end{array}$ & Reality \\
\hline Myth \#1 & Dichotomization & $\begin{array}{l}\text { - It is not appropriate to dichotomize otherwise continuous interval-ratio level } \\
\text { data (e.g., chronological age; see Harrell, 2020); if a particular statistical } \\
\text { model is not amenable to the distribution of scores present in one's data, it is } \\
\text { in the researcher's best interests to adopt a model that can handle such data. }\end{array}$ \\
\hline Myth \#2 & Nested Data & $\begin{array}{l}\text { - If data are nested (e.g., employees nested within supervisors; observations } \\
\text { nested within-person across tasks or over time), the resulting non- } \\
\text { independence cannot be ignored (Hox et al., 2017; Raudenbush \& Bryk, } \\
\text { 2002; Snijders \& Bosker, 2011). }\end{array}$ \\
\hline Myth \#3 & Familywise Error & $\begin{array}{l}\text { - In conducting multiple related tests (e.g., post-hoc tests; exploratory } \\
\text { analyses), familywise error rates must be accounted for appropriately (e.g., } \\
\text { Rubin, 2017). }\end{array}$ \\
\hline Myth \#4 & Marginal Significance & $\begin{array}{l}\text { - The language of "marginal" statistical significance is not meaningful } \\
\text { (Pritschet et al., 2016). Under the assumption of a "true" null hypothesis (and } \\
\text { upholding other assumptions) p-values are uniformly distributed (see Robins } \\
\text { et al., 2000). }\end{array}$ \\
\hline Myth \#5 & P-Values & $\begin{array}{l}\text { - In terms of inferences, effect sizes matter more than } p \text {-values (Cohen, } \\
\text { 1990). }\end{array}$ \\
\hline Myth \#6 & Appropriate Models & $\begin{array}{l}\text { - It is important to use statistical models for their intended purposes. For } \\
\text { example, "true" multivariate analyses (e.g., MANOVA) really only make } \\
\text { sense in cases where testing hypotheses about composite outcomes are of } \\
\text { interest; if one's ultimate goal is to consider univariate tests, then it befits the } \\
\text { analyst to simply run such univariate tests (see Huang, 2020; Smith et al., } \\
\text { 2020). }\end{array}$ \\
\hline
\end{tabular}

